\title{
Outcome of patients treated for myelodysplastic syndromes with $5 q$ deletion after failure of lenalidomide therapy
}

\author{
Thomas Prebet ${ }^{1}$, Thomas Cluzeau ${ }^{2, *}$, Sophie Park ${ }^{3,4, *}$, Mikkael A. Sekeres ${ }^{5}$, Ulrich \\ Germing $^{6}$, Lionel Ades ${ }^{4,7}$, Uwe Platzbecker ${ }^{8}$, Katharina Gotze ${ }^{9}$, Norbert Vey ${ }^{4,10}$, \\ Esther Oliva $^{11}$, Mary M. Sugrue ${ }^{12}$, Cecile Bally ${ }^{4}$, Charikleia Kelaidi ${ }^{4}$, Najla Al Ali ${ }^{2}$, \\ Pierre Fenaux ${ }^{4,7}$, Steven D. Gore ${ }^{1, *}$ and Rami Komrokji ${ }^{2, *}$ \\ ${ }^{1}$ Moffit Cancer Center, Tampa, Florida, USA \\ ${ }^{2}$ Cote d'Azur University, Nice Sophia Antipolis University, Centre Hospitalier Universitaire de Nice, Nice, France \\ ${ }^{3}$ U1065, Mediterranean Center of Molecular Medecine, Nice, France \\ ${ }^{4}$ Groupe Francophone des Myelodysplasies, Hopital Saint Louis, Paris, France \\ ${ }^{5}$ Leukemia Program, Cleveland Clinic, Cleveland, OH, USA \\ ${ }^{6}$ Department Hematology, Oncology and Clinical Immunology, Heinrich Heine University, Dusseldorf, Germany \\ 7 Service Hematologie Senior, Hopital Saint Louis, Paris, France \\ ${ }^{8}$ Universitäts Klinikum Carl Gustav Carus, Dresden, Germany \\ 9 Klinikum Rechts der Isar, Technische Universität München, München, Germany \\ ${ }^{10}$ Departement d'Hematologie, Institut Paoli-Calmettes, Marseille, France \\ ${ }^{11}$ Hematology Unit, Azienda Ospedaliera Bianchi Melacrino Morelli, Reggio Calabria, Italy \\ ${ }^{12}$ Celgene Corporation, Summit, NJ, USA \\ * These authors have contributed equally to this work
}

Correspondence to: Thomas Prebet, email: Thomas.prebet@yale.edu

Keywords: myelodysplasia, outcome, lenalidomide

$\begin{array}{lll}\text { Received: April 18, } 2017 \quad \text { Accepted: April 24, } 2017 & \text { Published: June 14, } 2017\end{array}$

Copyright: Prebet et al. This is an open-access article distributed under the terms of the Creative Commons Attribution License 3.0 (CC BY 3.0), which permits unrestricted use, distribution, and reproduction in any medium, provided the original author and source are credited.

\section{ABSTRACT}

While lenalidomide (LEN) is the standard of care for the lower-risk myelodysplastic syndromes (MDS) patients with deletion $\mathbf{5 q}, \mathbf{3 5 \%}$ will not respond to or do not tolerate the drug. Moreover, most of the patients will lose their response after a few years. Defining the outcome of patients with LEN failure and determining the impact of subsequent therapies is therefore important to develop alternative strategies. Based on an international collaboration, we were able to compile a total of 392 patient cases of lower-risk MDS patients with 5q deletion and to analyze their outcome after failure of lenalidomide. The median survival following LEN failure was 23 months. We observed a negative impact on survival of advanced age, higher bone marrow blast count at LEN initiation, progression after LEN failure, and unfavorable cytogenetics. Among the treatment strategies, we observed a relatively prolonged survival of patients treated subsequently with hypomethylating agents and only a limited impact on survival of allogeneic transplantation. In conclusion, our work stresses the relatively short survival of this group of patient and defines the expected baseline for the needed future investigations in this group of patients.

\section{INTRODUCTION}

Myelodysplastic syndromes (MDS) are a heterogeneous group of diseases characterized by ineffective hematopoiesis, peripheral blood cytopenias, and a risk of evolution to acute myeloid leukemia [1]. Over the last decade, hypomethylating agents [24] (HMA) and lenalidomide [5, 6] (LEN) changed therapeutic approaches for MDS, offering for the first time treatments able to durably correct cytopenias and 
potentially to prolong survival. In the case of azacitidine, higher-risk patients experienced prolonged survival when compared to patients treated with conventional care but a vast majority of patients will eventually relapse or experience disease progression [7]. The outcome of patients experiencing failure of HMA is poor and several studies $[8,9]$ defined the basis on which we are currently trying to build innovative strategies in this setting. Lenalidomide has significant activity in lowerrisk MDS harboring deletion (del) 5q. The mechanism of action of the drug involves Cereblon, to which LEN binds [10], and Casein Kinase 1A1 [11]. LEN induces sustained hematological and cytogenetic responses with red blood cells (RBC) transfusion independence in the majority of patients. However, 30 to $40 \%$ of patients will not respond to or potentially will not tolerate the drug. Moreover, for responders, the median duration of response ranges is approximately two years [12, 13]. LEN has also been tested in higher-risk disease with del $5 q$ as single agent [14], in combination with HMA [15, 16], or with chemotherapy [17]; however a more limited success was observed. LEN has obtained Food and Drug Administration approval for transfusion-dependent anemia due to low- or intermediate-1-risk MDS associated with a del $5 \mathrm{q}$ with or without one additional cytogenetic abnormality, whereas the European Medicine Agency has restricted approval for those with isolated del $5 \mathrm{q}$ cytogenetic when other therapeutic options are insufficient or inadequate. The drug is still undergoing additional monitoring due to the lack of sufficient follow-up data.

There is no universally accepted second-line treatment for patients experiencing LEN failure and only a limited number of patients undergo allogeneic transplantation. Several groups of investigators are currently developing strategies for del $5 \mathrm{q}$ patients experiencing LEN failure. The use of HMAs may be an option, as well as new drugs such as imetelstat, immunotherapies, or TGF-Beta inhibitors[18, 19] but, to date, there is no standard of care, or ongoing phase III studies. To appropriately design and analyze trials in this population, it would be important to estimate their expected survival with current care options.

This study aimed to answer this question using a large retrospective cohort based on an international multicenter consortium of centers from Europe and North America.

\section{RESULTS}

\section{Patients' characteristics}

A total of 392 eligible patients treated between 2004 and 2015 and meeting eligibility criteria were included in the present study (see Table 1 for details). A majority of the patients were prospectively enrolled in clinical trials and compassionate use programs $(n=261,66 \%$, MDS-003 and MDS-004 studies, French lenalidomide compassionate use program) while MDS registries patients represented $34 \%$ of the total cohort. The number of patients were well balanced between US and Europe (216 and 176 patients respectively). As expected for a population defined by the presence of del 5q, the patients' characteristics were slightly different from the general population of MDS patients. The median age was only 70y (range [37-95]) and there was a female predominance ( $2 / 3$ of the patients). At diagnosis, CBC showed a median hemoglobin level of 9.2g/dl (range [3.8-13.6]) but preserved platelet counts (median platelet count: $223 \mathrm{G} / 1$, range [17-974]). The majority of patients had low bone marrow blast counts (median: $3 \%$ ). with only $23 \%$ of patients with RAEB-1. Of note, therapy-related MDS represented $16 \%$ of the cohort.

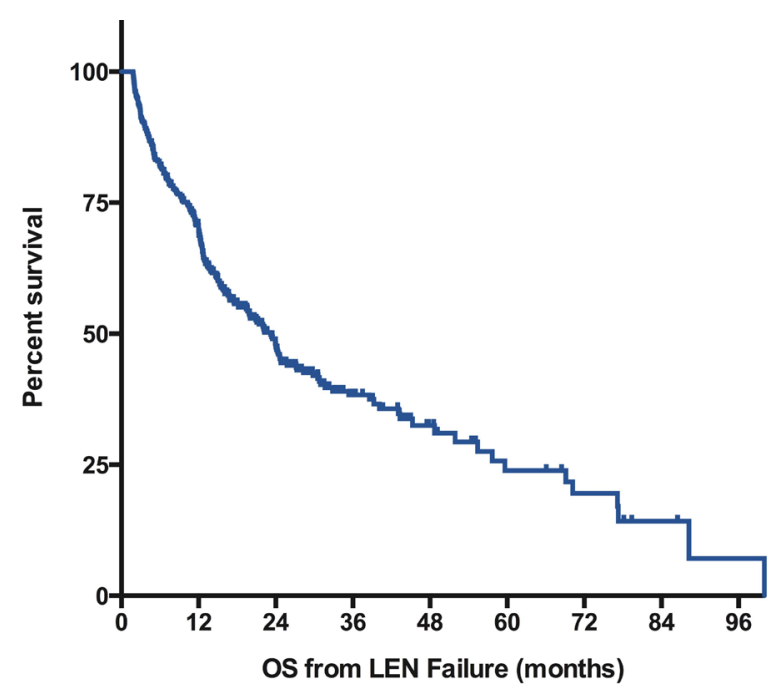

Figure 1: Overall Survival after failure of lenalidomide. Survival is defined from documentation of failure to death of any cause or last-follow-up and is expressed in months., LEN: lenalidomide. 
Table 1: Patients characteristics.

\begin{tabular}{|l|c|}
\hline Variable & 392 \\
\hline $\mathbf{N}=$ & $70 \mathrm{y}(37-95)$ \\
\hline Median age & $134(34 \%)$ \\
\hline Male Gender & \\
\hline WHO classification & $125(32 \%) / 97(25 \%)$ \\
\hline \multicolumn{1}{|c|}{ RA/ del5q } & $27(7 \%) / 41(10 \%)$ \\
\hline \multicolumn{1}{|c|}{ RARS/RCMD } & $91(23 \%)$ \\
\hline \multicolumn{1}{|c|}{ RAEB-1 Other } & $11(3 \%)$ \\
\hline Therapy related MDS & $61(16 \%)$ \\
\hline Median BM blast count (\%) & $3(0-9)$ \\
\hline Deletion (5q) & $230(61 \%)$ \\
\hline \multicolumn{1}{|c|}{ isolated } & $105(24 \%)$ \\
\hline \multicolumn{1}{|c|}{ Del(5q)+1 aberration } & $42(11 \%)$ \\
\hline \multicolumn{1}{|c|}{ FISH only } & $15(4 \%)$ \\
\hline RBC TD before LEN & $353(90 \%)$ \\
\hline Use of ESA before LEN & $155(39 \%)$ \\
\hline IPSS low/intermediate-1 & $13(3 \%)$ \\
\hline Use of HMA before LEN & $210(54 \%)$ \\
\hline LEN response & $296(76 \%)$ \\
\hline LEN initial dose 10mg daily & $9.5 \mathrm{~m}(1-68)$ \\
\hline LEN duration & $(41 \%) / 231(59 \%)$ \\
\hline
\end{tabular}

M/F: male/female, RA: refractory anemia, del5q: 5q syndrome, RARS: refractory anemia with ring sideroblasts, RCMD: Refractory cytopenia with multilineage dysplasia, RAEB: Refractory anemia with excess of blast, BM: bone marrow, K.: karyotype, RBC: Red blood cell, TD:transfusion dependency, LEN: lenalidomide, ESA: erythropoiesis stimulating agent, HMA: hypomethylating agents, m: month

The cytogenetic analysis confirmed an isolated del $5 q$ in a majority of patients $(61 \%)$. Twenty-four percents of patients harbored del $5 \mathrm{q}$ and an additional chromosomal abnormality and $11 \%$ of patients had a complex karyotype including del $5 \mathrm{q}$. An additional 15 patients (4\%) had del $5 \mathrm{q}$ only documented by FISH. Data on TP53 mutations were limited and only available in $10 \%$ of the patients, 7 patients harboring a TP53 mutation. Ninety percent of the patients were RBC transfusion dependent at the initiation of LEN. Use of prior treatments before LEN was uncommon with $39 \%$ of patients exposed to erythropoiesis stimulating agents (ESAs) and only 3\% previously treated with HMAs, reflecting the differences of indication and access to the drugs in the different countries.

$54 \%$ of patients responded to LEN with a median durations of treatment of 9.5 months overall, and 17 months for responding patients. Responding patients tended to have non-complex cytogenetics (response rate $57 \%$ vs $24 \%, p<0.001)$ and experienced a more prolonged survival after LEN initiation (median OS 50 months vs 28 months, $\mathrm{p}<0.001)$. LEN treatment schedules varied but most patients were treated using either the $10 \mathrm{mg} / \mathrm{d}$ for 3 weeks followed by 1 week rest ( $76 \%$ of the patients), or the $5 \mathrm{mg} / \mathrm{d}$ continuous schedule ( $23 \%$ of the patients), as previously described in the related publications[5, 12]. Thus, we decided to group patients by comparing the initial daily dose of the drug (i.e. $10 \mathrm{mg}$ vs less than $10 \mathrm{mg}$ ). Of note, 8 patients had combinations of LEN and ESA. Data on cytogenetic response were available for 207 patients with 83 pts achieving a cytogenetic CR or PR (40\%).

At the time of LEN failure, 141 patients stopped LEN for lack of efficacy (36\%, median duration of LEN 5 months), 152 pts for loss of HI without bone marrow progression (39\%, median duration of LEN 17 months), 56 pts stopped LEN due to toxicities (14\%, median duration of LEN 4 months), and 43 patients (11\%) progressed to AML or RAEB-2 (including 23 responders, median duration of LEN 7 months). The supplemental figure 1 shows the patient cohorting diagram for the study. After stopping LEN, an additional 109 patients progressed to AML during follow-up with a 2-year probability of progression of 34\% (supplemental figure 2).

\section{Outcome of patients after failure of Lenalidomide}

At last follow-up, 170 patients were alive and 222 had died. With a median follow-up of 22 months for survivors (range: [5-87]), the median overall survival was 23 months (IC95\% [20-27]) with a 5-year probability of survival of $24 \%$ (figure 1). Patients with isolated del $5 q$ 
Table 2: Multivariate analysis of outcome after lenalidomide failure.

\begin{tabular}{|c|c|c|c|c|}
\hline Variable & Median OS & HR & $95 \% \mathrm{CI}$ & $p$ value \\
\hline $\begin{array}{l}\text { Age below } 75 y \\
\text { Age } 75+\end{array}$ & $\begin{array}{l}27 \mathrm{~m} \\
18 \mathrm{~m}\end{array}$ & $\begin{array}{c}1 \\
1.64\end{array}$ & [1.24 - 2.18] & 0.001 \\
\hline $\begin{array}{l}\text { Adverse K no } \\
\text { Adverse K yes }\end{array}$ & $\begin{array}{l}24 \mathrm{~m} \\
15 \mathrm{~m}\end{array}$ & $\begin{array}{c}1 \\
1.65\end{array}$ & {$[1.07-2.55]$} & 0.03 \\
\hline $\begin{array}{l}\text { RAEB no } \\
\text { RAEB yes }\end{array}$ & $\begin{array}{l}24 \mathrm{~m} \\
18 \mathrm{~m} \\
\end{array}$ & $\begin{array}{c}1 \\
1.41\end{array}$ & {$[1.03-1.93]$} & 0.03 \\
\hline $\begin{array}{l}\text { SD } \\
\text { Loss HI } \\
\text { Intolerance } \\
\text { PD at failure }\end{array}$ & $\begin{array}{l}17 \mathrm{~m} \\
39 \mathrm{~m} \\
24 \mathrm{~m} \\
11 \mathrm{~m}\end{array}$ & $\begin{array}{c}1 \\
.64 \\
1.09 \\
2.367 \\
\end{array}$ & $\begin{array}{c}{[0.36-1.15]} \\
{[0.68-1.77][1.609-} \\
3.481]\end{array}$ & $\begin{array}{l}.14 \\
.73 \\
\mathbf{0 . 0 1} \\
\end{array}$ \\
\hline $\begin{array}{l}\text { No response to LEN } \\
\text { Response to LEN }\end{array}$ & $\begin{array}{l}17 \mathrm{~m} \\
27 \mathrm{~m}\end{array}$ & $\begin{array}{c}1 \\
1.04\end{array}$ & [0.64-1.70] & 0.86 \\
\hline
\end{tabular}

OS: overall survival, HR: Hazard ratio, CI: confidence interval, y: year, m: month, adverse K: adverse karyotype (per IPSS classification), RAEB: refractory anemia with excess of blasts (here limited to $5 \%$ to $10 \%$ bone marrow blasts), SD: stable disease, loss of HI: loss of hematologic improvement without bone marrow progression, PD: progressive disease at failure (to RAEB-2 or AML), LEN: lenalidomide.

$(\mathrm{n}=230)$ had a median survival of 24 months $(95 \%$ CI [1533]) and patients with a single additional chromosomal aberration $(\mathrm{n}=105)$ had a median OS of 22 months $(95 \% \mathrm{Ci}$ [16-28]). In contrast, patients with complex karyotypes including a del $5 \mathrm{q}(\mathrm{n}=42)$ had a shorter survival with a median OS of 15 months $(95 \% \mathrm{Ci}$ [9-22]). Considering the type of LEN failure, patients with relapse/secondary loss of HI ( $n=152)$ had the best outcome with a median OS of 39 months after LEN failure (95\%CI [27-51]) followed by patients with LEN intolerance $(n=56$, median OS 23 months 95\%CI [14-34]), and patients without response ( $\mathrm{n}=141$, median OS $17 \mathrm{~m}$ 95\%CI [11-24]). As expected, patients with progression to RAEB-2 or AML had the worst prognosis ( $\mathrm{n}=43$, median OS $11 \mathrm{~m} 95 \%$ CI [6-17]) (figure 2). Of note, in the subgroup of patients with nonadverse cytogenetics and experiencing secondary loss of HI, the median OS was 43 months (95\% CI [28-58]).

In univariate analysis, we observed a negative impact on survival of several factors: age $>74$ years (median OS 18 months vs. 27 months, $\mathrm{p}=0.002$ ), history

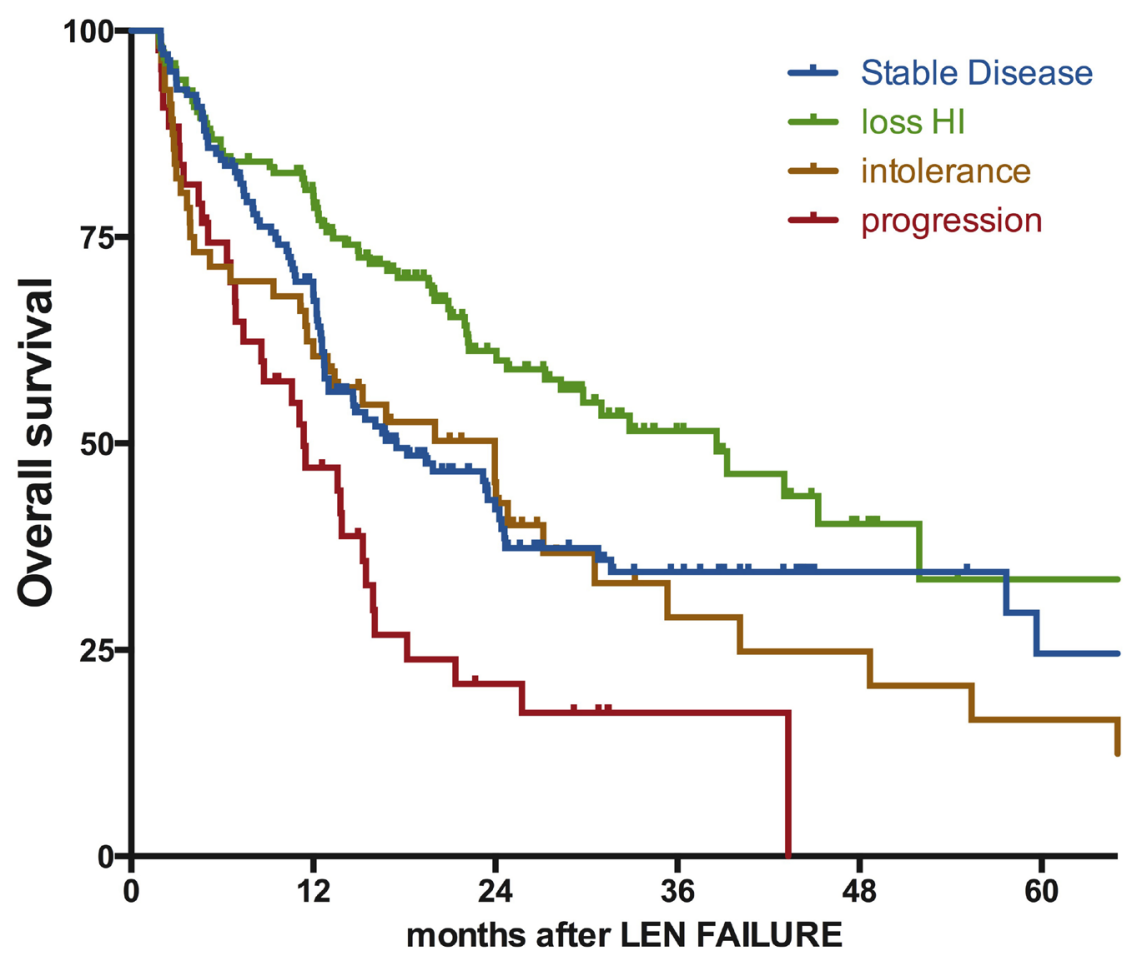

Figure 2: Impact of the type of failure on the outcome after failure of lenalidomide. Survival is defined from documentation of failure to death of any cause or last-follow-up and is expressed in months. SD: stable disease, loss of HI: loss of hematologic improvement without bone marrow progression, PD: progressive disease at failure (to RAEB-2 or AML), LEN: lenalidomide. 
of therapy-related MDS (median OS 18 months vs. 24 months, $p=0.08$ ), presence of excess of blasts at the time of initiation of LEN (median OS 15 months vs. 24 months, $\mathrm{p}=0.02$ ), presence of complex cytogenetics (median OS 15 months vs. 24 months, $\mathrm{p}=0.012$ ), absence of response to LEN (median OS 17 months vs. 27 months, $p=0.04$ ), reason for LEN failure (progression vs other; median OS 11 months vs. 24 months, $\mathrm{p}<0.001$ ). We did not observe any significant impact of gender, region (US vs. Europe), clinical trial participation, cytogenetics (isolated del $5 \mathrm{q}$ vs. 1 additional aberration), RBC transfusion dependence, IPSS (low vs. Intermediate-1), LEN schedule, or LEN duration. Our findings were confirmed in a subgroup analysis performed for patients treated with LEN for at least 6 months (median OS from failure of 39 months for loss of HI vs. 17 months for SD, 12 months for intolerant patients and 14 months for progression, $\mathrm{p}<0.001$, supplemental figure 3). We performed a subgroup analysis for patients with available cytogenetic response data $(n=207)$. Achieving a prior cytogenetic CR or PR had no impact on outcome after failure of LEN (median OS of 17 months vs. 15 months for patients without cytogenetic response, $\mathrm{p}=\mathrm{NS}$ ). In the small subgroup of patients with TP53 mutations, we did not observe any significant difference of survival with 1-year probability of OS of 57 and $59 \%$ respectively. Of note, 5 of the 7 mutated patients were allotransplanted in salvage.

The multivariate model included all the above mentioned variables showing an impact on outcome (table 2). We confirmed the detrimental effect of age (HR 1.64,
95\%CI [1.24 - 2.18], $\mathrm{p}=0.001)$, bone marrow blast excess at LEN initiation (HR 1.41, 95\%CI [1.03 - 1.93], $\mathrm{p}=0.03$ ), bone marrow progression at $\mathrm{LEN}$ failure (HR 1.9, 95\% CI [1.14 - 3.23], $\mathrm{p}=0.01)$, and Complex karyotype (HR $1.65,95 \%$ CI [1.07-2.55], $\mathrm{p}=0.03)$. We also performed a separated model to analyze the cumulative incidence of AML in patients without progression at the time of LEN failure. As shown in supplemental table 2, complex karyotype, bone marrow blast excess at LEN initiation, and treatment with HMA prior to LEN initiation had a detrimental impact on the incidence of AML. There was no documented impact of age, use of ESA prior to LEN, response to LEN. The duration of exposure to LEN (+/- 6 months) had a significant impact in univariate analysis that was not confirmed in the multivariate model.

\section{Impact of treatment strategies after Lenalidomide failure}

Details of the first treatment given after LEN failure were available in 232 patients (59\% of the cohort, figure $3)$. Patient's characteristics for each treatment group are described in supplemental table 1. Best supportive care was the only treatment given for 78 patients $(34 \%$ of the patients with available data) with a median survival of 23 months (95\%CI [18-29] months). Patients receiving any active treatment had prolonged survival compared to those receiving BSC only (median OS 49 months vs. 23 months, $\mathrm{p}=0.003$ ) but the impact of treatment varied

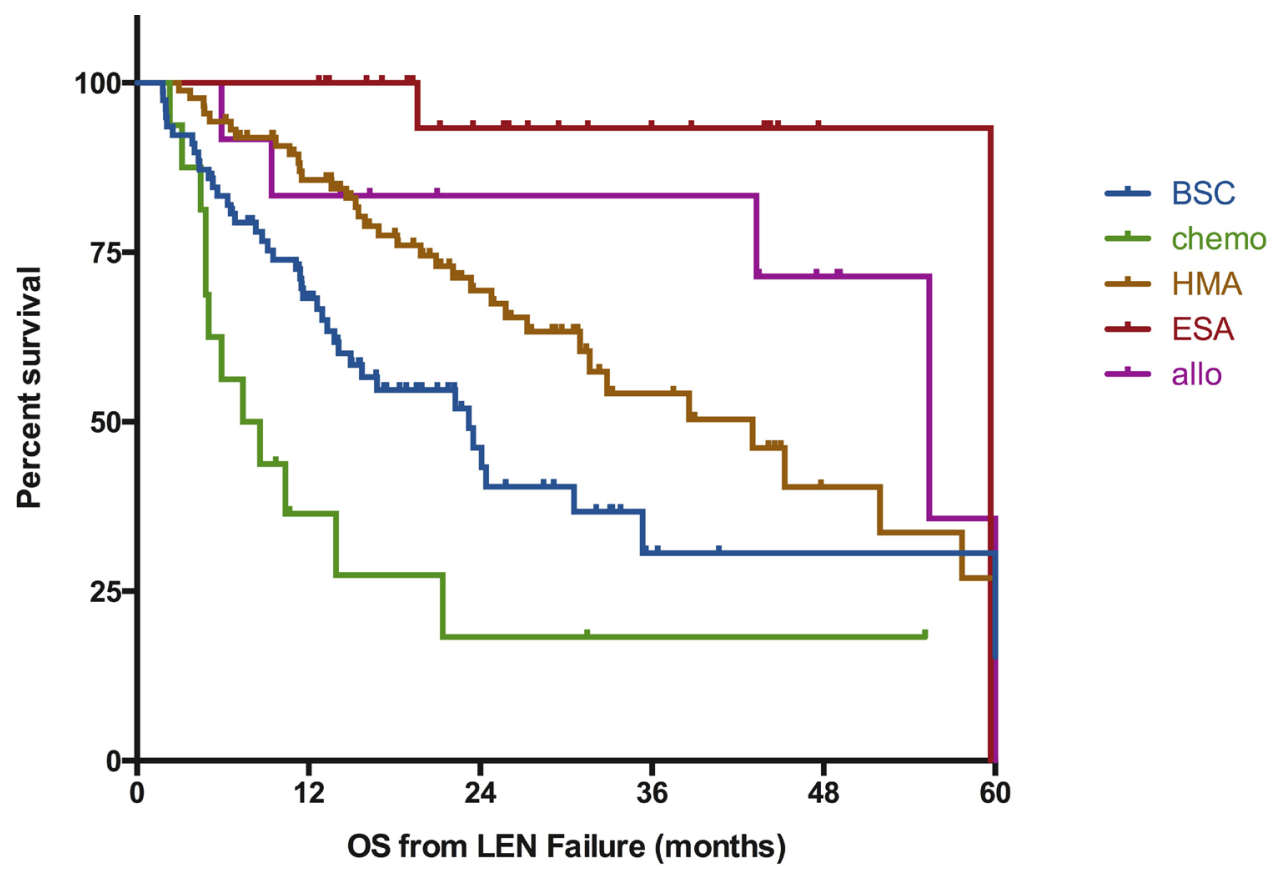

Figure 3: Impact of conventional therapies on outcome after failure of lenalidomide. Survival is defined from documentation of failure to death of any cause or last-follow-up and is expressed in months. BSC; best supportive care, chemo: chemotherapy (including AML like induction regimen or lower dose standard chemo), HMA: hypomethylating agents, ESA: erythropoiesis stimulating agents, Allo: allogeneic transplantation, LEN: lenalidomide. 
with treatment type. Consistent with the dismal outcome of patients with disease progression, patients treated with chemotherapy $(n=16)$ had the shortest overall survival ( 7 months) with 3 of the 12 patients with available data achieving CR (25\%). The larger group of patient $(n=91$, $39 \%$ ) received HMA, with $71 \%$ of them receiving azacitidine and 29\% receiving decitabine. Their overall survival was improved as compared to BSC in univariate analysis (median OS 39 months vs. 23 months, $\mathrm{p}=0.004$ ) and in a multivariate model (Supplementary Table 3, $\mathrm{HR}=0.3495 \% \mathrm{CI}[0.21-0.56]), \mathrm{p}=0.002)$. Of the $71 \mathrm{pts}$ treated with HMA with evaluable response, 32 (45\%) achieved a clinical response including $11 \mathrm{CR}$ or PR (15\%). The median OS of the 18 patients who received HMA in the context of progressive disease was 16 months ( $p=0.13$ compared to intensive chemo). Interestingly, 4 out of 5 patients with TP53 mutation responded to HMA therapy and 3 bridged to allogeneic transplantation. A group of 22 patients was treated with ESAs, including 10 who already had received ESAs prior to LEN. The median overall survival of the ESAs group was 59 months, with no notable difference of survival between patients with or without prior exposure to ESAs. Of note, only 2 patients responded to ESAs therapy after LEN (2/18 with available data) including 1 patient with prior exposure to ESAs before LEN. Allogeneic transplantation was performed in 30 patients with transplantation performed immediately after LEN failure in 12 cases and after other salvage therapies in the remaining 18 cases. Median OS was 52 months (55 months for patients allotransplanted directly after LEN failure) and was not significantly improved as compared to patients treated with other strategies (median OS 35 months, $p=0.7$ ). As seen on figure 3, we did not observe any long term survival plateau for allotransplanted patients. Finally, 13 patients $(6 \%)$ were treated with other modalities (Thalidomide $(n=4)$, Antithymocyte globulin $(n=3)$, danazol $(n=1)$, ruxolitinib $(n=1)$, clinical trials $(n=4))$ and those numbers were too low to evaluate outcome.

\section{DISCUSSION}

This is the first large study focused on the outcome of MDS patients with deletion $5 \mathrm{q}$ after LEN failure. We report a median survival of 23 months for patients treated with best supportive care. This will help to define a baseline of future investigations. We showed that outcome was heterogeneous and influenced by patients' characteristics and type of LEN failure. Finally, we observed that standard of care strategies used after LEN may have some potential benefit in patients treated with HMAs, acknowledging the limitation of a non-prospective design.

As previously mentioned, the combination of del $5 q$ and LEN treatment is a unique paradigm in the MDS field. We know from prior studies of patients with del $5 q$ that conventional treatments, ESAs for instance, are probably less effective in these patients as compared to those without the deletion [20] and that LEN is able to trigger deeper responses with cytogenetic remission, potentially modifying the natural history of the disease. This may explain why only a minority of our patients were exposed to ESAs prior to LEN, as a significant number of clinicians will choose to directly treat with LEN. This point is still a matter of debate in the hematology community. In our hands and keeping in mind the potential limitations of our cohort, we observed a similar overall survival calculated from diagnosis for patients previously treated with ESAs or not (median OS 82 months vs. 77 months respectively, $\mathrm{p}=0.16)$.

We need to acknowledge that the retrospective nature of our study exposes to some limitations and bias but, indeed, there are few other ways to evaluate standard of care strategies in these settings. In our study, the large number of patients and the high proportion of patients included in clinical trials and prospective compassionate programs limits the risk selection bias. Moreover, patients from the centers databases were consecutively registered and cases included in our study were only selected to fulfill the inclusion criteria listed in the methods section. Despite the high number of patients, some potentially interesting variables were not available in a majority of cases and could not integrated in the analyses: comorbidities scorings were only documented for 95 patients and TP53 mutation status was only available for 39 patients. The impact of TP53 mutations[21, 22] and P53 expression[23] in the progression of MDS seems especially important in the context of $5 \mathrm{q}$ deletion. The frequency of TP53 mutation in our small subgroup (7/39 patients harboring a mutation, 18\%) matches what has been presented in the prior studies dedicated to del 5q MDS [21, 22] as well as what was described in large-scale genomic studies [24]. This point is interesting, as we may have expected a slightly more elevated incidence in a group of patients selected for LEN failure. The relatively high response to salvage HMA is in line with the recent New England Journal of Medicine publication[25].

Our multivariate analysis model for overall survival showed a detrimental impact of variables expected to be associated with a negative outcome: older age, cytogenetic complexity, and presence of an excess of blasts at the initiation of lenalidomide. Interestingly, we also showed that treatment related variables also have some influence. The progression to a more aggressive presentation (RAEB-2 or AML) strongly impaired the chances of longterm survival and was associated with a poor outcome when treated with conventional therapies ( 7 months for conventional chemo, 16 months for hypomethylating agents). In contrast, patients who relapsed after achieved an erythroid response seemed to have a more favorable outcome with a median OS of 39 months. Even if it can be argued that it represents a selection bias, we can speculate 
that it may reflect the changes in the natural history of the disease induced by LEN. This is also suggested by the absence of impact on outcome of the duration of LEN by itself.

The analysis of the treatment strategies used after LEN failure must be interpreted with caution as the choice of therapy was driven by the type of failure and by the patient medical condition (Supplementary Table 1). Patients with progression to AML were treated aggressively and had a dismal outcome, while younger patients with less comorbidities and stable lower-risk disease were more commonly treated with allogeneic transplantation and experienced a relatively prolonged survival. Of note, we were not able to demonstrate a significant survival benefit of allogeneic transplantation in either the group of patients allotransplanted upfront or in the whole group of allotransplanted patients, acknowledging that one of the potential limitation of our analysis remains the relatively small number of patients. Finally, we showed a relatively favorable outcome of patients treated with HMAs. It is important to notice that the majority of patients exposed to HMA did not had bone marrow progression. Median overall survival was strongly influenced by progression in this subgroup: 45 months for patients without progression as compared to 16 months for patients treated with HMA for progression $(\mathrm{p}<0.001)$. Moreover, we did not observe any long-term survival plateau (as shown in figure 3). This improved outcome for the sequence LEN / HMA has already been suggested in non-del5q MDS patients [26] and should warrant further investigation with HMA used as a potential backbone of combinations therapies. The type and schedule of HMA that could be used remain an open question.

In conclusion, our study defined the expected baseline for future clinical investigation in the settings of MDS with $5 q$ deletion experiencing LEN failure. Despite the very good results of LEN in this group of patient, not all patients respond and responses are transient. The survival of this group of usually younger patients is relatively short for patients that only had access to supportive care. Hypomethylating agents appeared here as a potential backbone of future investigations. Finally, our results stress again the need to focus basic and translational research on new ways to eradicate the $5 \mathrm{q}$ clone.

\section{PATIENTS AND METHODS}

\section{Patient selection}

This study was an international collaboration which included patient treated in clinical trials $[5,6,12]$, prospective compassionate use programs [27], as well as patients followed in MDS registries in the different centers. Patients were eligible for the study if they fulfilled the following criteria: 1: diagnosis of MDS according to WHO 2008 classification [28] 2: presence of a del 5q confirmed by conventional cytogenetics and/or fluorescent in situ hybridization (FISH) techniques 3: treatment with single agent LEN for the MDS and 4: documentation of LEN failure (see below for the definition of LEN failure). All patients gave consent for the use of their clinical and biological data and Yale University internal review board has approved the study.

Patients with higher risk disease refractory anemia with excess of blast-2 (RAEB-2) or acute myeloid leukemia (AML) were excluded as were patients treated with combinations of LEN with other active treatments (chemotherapy, HMA). However, combinations with hematopoietic growth factors or iron chelation therapies were accepted. Patients treated with LEN as remission maintenance therapy, for instance after allogeneic transplantation, were also excluded from the analysis.

Cytogenetic risk was assessed based on International Prognostic Scoring System (IPSS) [29].

\section{Definition of Lenalidomide failure}

Clinical and cytogenetic responses were evaluated according to the international working group 2006 MDS criteria [30]. The initial intent was to treat patients for 3 to 6 months with disease assessment every 8 weeks. Responding patients were treated until documentation of treatment failure. We defined 4 different categories: absence of response, bone marrow progression during treatment with or without prior response, secondary failure (loss of a prior hematological response without bone marrow progression), and intolerance (treatment stopped related to adverse event, with or without prior response).

\section{Statistical methods}

Data were summarized by frequency and percentage for categorical variables. For continuous variables, the median and range were computed. All results are presented with their $95 \%$ confidence intervals. Statistical tests were two-sided at the $5 \%$ level of significance. To investigate the association between continuous variables and categorical variables, univariate statistical analyses were performed using non-parametric Wilcoxon rank sum test, Chi square test or Fisher's exact test when appropriate. Survival rates were estimated by the KaplanMeier method and log-rank test. Overall survival (OS) was measured from the date of LEN failure until death from any cause with observation ending at the date of last contact for patient last known to be alive. Patients without events were censored at the date of last follow up. Multivariate analyses were performed using a Cox proportional hazards method. All variables with $\mathrm{p}$-value 
below 0.15 in univariate analysis were included in the Cox model using a stepwise procedure selection. Statistical tests were performed using SPSS 21.0 and graphs were designed using PRISM 6 software.

\section{Author contributions}

TP designed study, treated patients, collected data, analyzed data, and wrote the manuscript.

TC collected data, analyzed data, and reviewed the manuscript.

SP, UP, UG, KG, NV, MSe, EO, treated patients, collected data, and reviewed the manuscript.

NAA, MSu collected data, and reviewed the manuscript.

PF, SG, RK treated patients, analyzed data, and reviewed the manuscript.

\section{ACKNOWLEDGMENTS}

The authors would like to thank all the teams from the different participating centers implicated in the care of patients and collect of the data.

\section{CONFLICTS OF INTEREST}

TP received research support by Celgene.

EO has received consultancy and lecturing fees from Celgene.

MS is an employee of Celgene.

UP received honoraria and research support: Celgene, Amgen, Novartis, and Janssen.

\section{Editorial note}

This paper has been accepted based in part on peerreview conducted by another journal and the authors' response and revisions as well as expedited peer-review in Oncotarget.

\section{REFERENCES}

1. Greenberg PL, Attar E, Bennett JM, Bloomfield CD, Borate U, De Castro CM, Deeg HJ, Frankfurt O, Gaensler K, Garcia-Manero G, Gore SD, Head D, Komrokji R, et al. Myelodysplastic syndromes: clinical practice guidelines in oncology. J Natl Compr Canc Netw. 2013; 11:838-74.

2. Fenaux P, Mufti GJ, Hellstrom-Lindberg E, Santini V, Finelli C, Giagounidis A, Schoch R, Gattermann N, Sanz G, List A, Gore SD, Seymour JF, Bennett JM, et al, and International Vidaza High-Risk MDS Survival Study Group. Efficacy of azacitidine compared with that of conventional care regimens in the treatment of higher-risk myelodysplastic syndromes: a randomised, open-label, phase III study. Lancet Oncol. 2009; 10:223-32.

3. Kantarjian H, Issa JP, Rosenfeld CS, Bennett JM, Albitar M, DiPersio J, Klimek V, Slack J, de Castro C, Ravandi F, Helmer R 3rd, Shen L, Nimer SD, et al. Decitabine improves patient outcomes in myelodysplastic syndromes: results of a phase III randomized study. Cancer. 2006; 106:1794-803.

4. Silverman LR, McKenzie DR, Peterson BL, Holland JF, Backstrom JT, Beach CL, Larson RA. Further analysis of trials with azacitidine in patients with myelodysplastic syndrome: studies 8421, 8921, and 9221 by the Cancer and Leukemia Group B. J Clin Oncol. 2006; 24: 3895-903. https://doi.org/10.1200/JCO.2005.05.4346.

5. List A, Dewald G, Bennett J, Giagounidis A, Raza A, Feldman E, Powell B, Greenberg P, Thomas D, Stone R, Reeder C, Wride K, Patin J, et al, and Myelodysplastic Syndrome-003 Study Investigators. Lenalidomide in the myelodysplastic syndrome with chromosome $5 \mathrm{q}$ deletion. N Engl J Med. 2006; 355:1456-65.

6. List A, Kurtin S, Roe DJ, Buresh A, Mahadevan D, Fuchs D, Rimsza L, Heaton R, Knight R, Zeldis JB. Efficacy of lenalidomide in myelodysplastic syndromes. N Engl J Med. 2005; 352:549-57.

7. Santini V, Prebet T, Fenaux P, Gattermann N, Nilsson L, Pfeilstöcker M, Vyas P, List AF. Minimizing risk of hypomethylating agent failure in patients with higher-risk MDS and practical management recommendations. Leuk Res. 2014; 38:1381-91.

8. Prébet T, Gore SD, Esterni B, Gardin C, Itzykson R, Thepot S, Dreyfus F, Rauzy OB, Recher C, Adès L, Quesnel B, Beach CL, Fenaux P, Vey N. Outcome of high-risk myelodysplastic syndrome after azacitidine treatment failure. J Clin Oncol. 2011; 29:3322-27.

9. Jabbour E, Garcia-Manero G, Batty N, Shan J, O'Brien S, Cortes J, Ravandi F, Issa JP, Kantarjian H. Outcome of patients with myelodysplastic syndrome after failure of decitabine therapy. Cancer. 2010; 116:3830-4. https://doi. org/10.1002/cncr.25247.

10. Jonasova A, Bokorova R, Polak J, Vostry M, Kostecka A, Hajkova H, Neuwirtova R, Siskova M, Sponerova D, Cermak J, Mikulenkova D, Cervinek L, Brezinova J, et al. High level of full-length cereblon mRNA in lower risk myelodysplastic syndrome with isolated $5 \mathrm{q}$ deletion is implicated in the efficacy of lenalidomide. Eur J Haematol. 2015; 95:27-34.

11. Krönke J, Fink EC, Hollenbach PW, MacBeth KJ, Hurst SN, Udeshi ND, Chamberlain PP, Mani DR, Man HW, Gandhi AK, Svinkina T, Schneider RK, McConkey M, et al. Lenalidomide induces ubiquitination and degradation of CK1 $\alpha$ in $\operatorname{del}(5 q)$ MDS. Nature. 2015; 523:183-88.

12. Fenaux P, Giagounidis A, Selleslag D, Beyne-Rauzy O, Mufti G, Mittelman M, Muus P, Te Boekhorst P, Sanz G, Del Cañizo C, Guerci-Bresler A, Nilsson L, Platzbecker 
U, et al, and MDS-004 Lenalidomide del5q Study Group. A randomized phase 3 study of lenalidomide versus placebo in RBC transfusion-dependent patients with Low-/ Intermediate-1-risk myelodysplastic syndromes with del5q. Blood. 2011; 118:3765-76.

13. Zeidan AM, Gore SD, McNally DL, Baer MR, Hendrick F, Mahmoud D, Davidoff AJ. Lenalidomide performance in the real world: patterns of use and effectiveness in a Medicare population with myelodysplastic syndromes. Cancer. 2013; 119:3870-78.

14. Adès L, Boehrer S, Prebet $\mathrm{T}$, Beyne-Rauzy O, Legros L, Ravoet C, Dreyfus F, Stamatoullas A, Chaury MP, Delaunay J, Laurent G, Vey N, Burcheri S, et al. Efficacy and safety of lenalidomide in intermediate- 2 or high-risk myelodysplastic syndromes with $5 \mathrm{q}$ deletion: results of a phase 2 study. Blood. 2009; 113:3947-52.

15. Sekeres MA, Othus M, List AF, Odenike O, Stone RM, Gore SD, Litzow MR, Buckstein R, Fang M, Roulston D, Bloomfield CD, Moseley A, Nazha A, et al. Randomized Phase II Study of Azacitidine Alone or in Combination With Lenalidomide or With Vorinostat in Higher-Risk Myelodysplastic Syndromes and Chronic Myelomonocytic Leukemia: North American Intergroup Study SWOG S1117. J Clin Oncol. 2017; 35:2745-2753.

16. Sekeres MA, Gundacker H, Lancet J, Advani A, Petersdorf S, Liesveld J, Mulford D, Norwood T, Willman CL, Appelbaum FR, List AF. A phase 2 study of lenalidomide monotherapy in patients with deletion $5 \mathrm{q}$ acute myeloid leukemia: Southwest Oncology Group Study S0605. Blood. 2011; 118:523-28.

17. Ades L, Prebet T, Stamatoullas A, Recher C, Guieze R, Raffoux E, Bouabdallah K, Hunault M, Wattel E, Stalnikiewicz L, Toma A, Dombret H, Vey N, et al. Lenalidomide (LEN) Combined To Intensive Chemotherapy (IC) In AML and Higher Risk MDS With Del 5q. Results Of a Phase I/II Study Of The Groupe Francophone Des Myelodysplasies (GFM). Haematologica. 2017; 102: 728735.

18. Platzbecker U, Germing U, Giagounidis A, Goetze K, Kiewe P, Mayer K, Ottman O, Radsak M, Wolff T, Haase D, Hankin M, Wilson D, Laadem A, et al. Luspatercept (ACE-536) Increases Hemoglobin and Reduces Transfusion Burden in Patients with Low or Intermediate-1 Risk Myelodysplastic Syndromes (MDS): Preliminary Results from a Phase 2 Study. Haematologica 2015; EHA abstract book.

19. Komrokji R, Garcia-Manero G, Ades L, Laadem A, Vo B, Prebet T, Stamatoullas A, Boyd D, Delaunay J, Steensma DP, Sekeres M, Beyne Rauzy O, Zou J, et al. A Phase 2, Dose-Finding Study of Sotatercept (ACE-011) in Patients With Lower-Risk MDS and Anemia Requiring Transfusion. Haematologica. 2015; EHA abstract book.

20. Kelaidi C, Park S, Brechignac S, Mannone L, Vey N, Dombret H, Aljassem L, Stamatoullas A, Adès L, Giraudier S, de Botton S, Raynaud S, Lepelley P, et al, and Groupe
Francophone des Myélodysplasies (GFM). Treatment of myelodysplastic syndromes with $5 \mathrm{q}$ deletion before the lenalidomide era; the GFM experience with EPO and thalidomide. Leuk Res. 2008; 32:1049-53.

21. Jädersten M, Saft L, Smith A, Kulasekararaj A, Pomplun S, Göhring G, Hedlund A, Hast R, Schlegelberger B, Porwit A, Hellström-Lindberg E, Mufti GJ. TP53 mutations in lowrisk myelodysplastic syndromes with del $(5 \mathrm{q})$ predict disease progression. J Clin Oncol. 2011; 29:1971-79.

22. Sebaa A, Ades L, Baran-Marzack F, Mozziconacci MJ, Penther D, Dobbelstein S, Stamatoullas A, Récher C, Prebet T, Moulessehoul S, Fenaux P, Eclache V. Incidence of 17p deletions and TP53 mutation in myelodysplastic syndrome and acute myeloid leukemia with $5 \mathrm{q}$ deletion. Genes Chromosomes Cancer. 2012; 51:1086-92.

23. Saft L, Karimi M, Ghaderi M, Matolcsy A, Mufti GJ, Kulasekararaj A, Göhring G, Giagounidis A, Selleslag D, Muus P, Sanz G, Mittelman M, Bowen D, et al. p53 protein expression independently predicts outcome in patients with lower-risk myelodysplastic syndromes with del(5q). Haematologica. 2014; 99:1041-49.

24. Papaemmanuil E, Gerstung M, Malcovati L, Tauro S, Gundem G, Van Loo P, Yoon CJ, Ellis P, Wedge DC, Pellagatti A, Shlien A, Groves MJ, Forbes SA, et al, and Chronic Myeloid Disorders Working Group of the International Cancer Genome Consortium. Clinical and biological implications of driver mutations in myelodysplastic syndromes. Blood. 2013; 122:3616-27.

25. Welch JS, Petti AA, Miller CA, Fronick CC, O’Laughlin M, Fulton RS, Wilson RK, Baty JD, Duncavage EJ, Tandon B, Lee YS, Wartman LD, Uy GL, et al. TP53 and Decitabine in Acute Myeloid Leukemia and Myelodysplastic Syndromes. N Engl J Med. 2016; 375:2023-36.

26. Zeidan AM, Al Ali NH, Padron E, Lancet J, List A, Komrokji RS. Lenalidomide Treatment for Lower Risk Nondeletion 5q Myelodysplastic Syndromes Patients Yields Higher Response Rates When Used Before Azacitidine. Clin Lymphoma Myeloma Leuk. 2015; 15:705-10.

27. Le Bras F, Sebert M, Kelaidi C, Lamy T, Dreyfus F, Delaunay J, Banos A, Blanc M, Vey N, Schmidt A, Visanica S, Eclache V, Turlure P, et al. Treatment by Lenalidomide in lower risk myelodysplastic syndrome with 5q deletion- the GFM experience. Leuk Res. 2011; 35:1444-48.

28. Vardiman JW, Thiele J, Arber DA, Brunning RD, Borowitz MJ, Porwit A, Harris NL, Le Beau MM, HellströmLindberg E, Tefferi A, Bloomfield CD. The 2008 revision of the World Health Organization (WHO) classification of myeloid neoplasms and acute leukemia: rationale and important changes. Blood. 2009; 114:937-51.

29. Greenberg P, Cox C, LeBeau MM, Fenaux P, Morel P, Sanz G, Sanz M, Vallespi T, Hamblin T, Oscier D, Ohyashiki K, Toyama K, Aul C, et al. International scoring system for evaluating prognosis in myelodysplastic syndromes. Blood. 1997; 89:2079-88. 
30. Cheson BD, Greenberg PL, Bennett JM, Lowenberg B, Wijermans PW, Nimer SD, Pinto A, Beran M, de Witte TM, Stone RM, Mittelman M, Sanz GF, Gore SD, et al. Clinical application and proposal for modification of the International Working Group (IWG) response criteria in myelodysplasia. Blood. 2006; 108:419-25. 